\title{
Performance of Loaded Thermal Storage Unit With A Commercial Phase Change Materials Based on Energy and Exergy Analysis
}

\author{
Abdullah N. Olimat a, Ahmad S. Awad b, Faisal M.AL-Gathain", Nabeel Abu \\ Shaban $^{\mathrm{d}}$ \\ ${ }^{a}$ Fire Safety Engineering Department, Prince Al-Hussein Bin Abdullah II Academy of Civil Protection, Al-Balqa' Applied University \\ Jordan, P. O. Box: 30, Amman (11511), Jordan \\ ${ }^{b}$ Mechanical Engineering Department, Faculty of Engineering Technology, Al-Balqa' Applied University, P. O. Box: 330116, Amman \\ (11134), Jordan. Country \\ c Faculty of Engineering Technology, Al-Balqa' Applied University, P. O. Box: 179, Tafila (66110), \\ d Mechanical Engineering Department, Alzaytoonah University, Amman,Jordan.
}

\begin{abstract}
This work presents an energy/exergy analysis to investige performance of thermal storage unit which loaded with a commercial phase change material (Plus ICE H190). The influence of fluid parameters on the energy/exergy effectiveness was examined. The temporal changes of the energy and exergy rate and performace of the storage unit are obtained in the results. Latent heat principle is considered an efficient method to gain a higher effectiveness of system from an energy and exergy aspects. The fluid mass flow rate during charging and discharging periods were $2.50 \mathrm{~kg} / \mathrm{min}$ and $1.26 \mathrm{~kg} / \mathrm{min}$, respectively. The results showed a significant increase of thermal resistance on the thermal storage unit performance. Fluid and phase change material show significant temperature difference on the rate of energy/exergy quantites and the time of melting or soldification. Ther results indicated that the average rate of energy and exergy were $1.3 \mathrm{~kW}$ and $0.54 \mathrm{~kW}$, respectively. Wheras, energy and exergy average rate during discarging periods were $1.1 \mathrm{~kW}$ and $0.31 \mathrm{~kW}$, respectively. Also, the global rate during the experimetal periods were about $84 \%$ and $54 \%$, respectively.
\end{abstract}

Keywords: phase change materials (PCMs); thermal storage unit (TSU); temperature gradient; energy; exergy.

Article History: Received July $6^{\text {th }}$ 2017; Received in revised form September 15 ${ }^{\text {th }}$ 2017; Accepted 25 $5^{\text {th }}$ Sept 2017; Available online How to Cite This Article: Olimat, A.N., Awad, A.S., Al-Gathain, F.M., and Shaban, N.A.. (2017) Performance of Loaded Thermal Storage Unit With A Commercial Phase Change Materials Based on Energy and Exergy Analysis. International Journal of Renewable Energy Develeopment, 6(3),283-290.

https://doi.org/10.14710/ijred.6.3.283-290

\section{Introduction}

The expected energy need for the world may be doubled by 2050 and will be tripled by the end of the century (Salwa et al 2014). Many countries are going to use renewable energy resources to overcome the sharply increased on energy need. The main source of renewable energy that can be converted to energy is solar which can be stored and used later in several applications. In a solar energy system, thermal storage unit (TSU) is concerned by many researchers in particular when there are temporal variations between supplies and demands. The thermal energy may be stored either in sensible heat or latent heat approach. Energy storage topic integrated with high latent enthalpy of phase change materials (PCMs) is a hot topic for many researchers around the world (Farid et al. 2004). The analysis of energy storage systems (ESS) is essential for efficient utilization of latent energy storage in order to increase performance of storage. The energy analysis is conducted on the basis of the first law thermodynamics whereas the exergy analysis is conducted with respect to the second law of thermodynamics. Energy analysis of latent heat in ESS based on the thermodynamics first law only does not reflect the usefulness of stored energy (Verma et al 2008). Information depending on the quality of energy stored and released is not enough for energy system performance evaluation on the basis of energy analysis

*Corresponding author: olimat91@gmail.com 
Citation: Olimat, A.N., Awad, A.S., Al-Gathain, F.M., and Shaban, N.A.. (2017) Performance of Loaded Thermal Storage Unit With A Commercial Phase Change Materials Based on Energy and Exergy Analysis. Int. Journal of Renewable Energy Development, 6(3),283-290, doi.org/ijred.6.3.283-290

P a g e | 284

only. Thus, exergy analysis depends on second law has been adopted by many researches (Erek and Dincer, 2009 ; Aghbalou and Badia, 2006) to overcome the inadequacy of energy analysis. Jegadheeswarm and Pohekar (2010) numerically analyzed the energy and exergy of a particle dispersed latent ESS. They found that the exergy analysis based on the performance evaluation of latent heat was more perspective measures than that of energy analysis and reflected the true potential of the system under different input parameters. Gang (2015) summarized comprehensive latent in a storage system using energy and exergy performance with various effect factors such as; mass flow rate of fluid, inlet temperature of fluid, number and type of PCMs, additives for PCMs, datum temperatures, storage unit dimensions, and exchange surface area. Mohamad et al (2016) studied, theoretically, the exergy analysis method to calculate the magnitude of exergy losses in solar desalination still combined with energy storage unit and charged with a phase change material. They concluded that the latent heat increased the water productivity and reduced the exergy efficiency. Sari et al (2004) examined both laws of thermodynamics analysis for performance evaluation of closed latent heat in an ESS using calcium hexahydrate. Their results showed that the mean energy and exergy efficiency were $55.20 \%$ and $34.83 \%$, respectively. The adsorption of cold energy storage unit for space cooling applications was investigated based on energy and exergy performance (Gang et al 2014). Their results showed that the fluid inlet temperature of the evaporator chamber significantly affected the energy and exergy performance in comparison with mass flow rate of the evaporator chamber fluid. The analysis was performed in a solar thermal power plant located in Shiraz, Iran (Mahfuz et al. 2014) Computational exergy analysis was used to examine the possibilities of improving solar power plant with integrating $\mathrm{PCM}$ s storage. They concluded that the energy and exergy efficiency without PCMs storage was $30 \%$ and $10 \%$, respectively. In addition, they found the overall exergy efficiency achieved by using PCMs storage along with the solar collector was about 30\%. Kaushik et al. (2011) reviewed the analysis of plants stimulated by coal and gas. Their main result was the useful energy loss couldn't be justified applying the first law of thermodynamics, as it doesn't differentiate between the energy quality and quantity. Several investigations have been conducted to analysis solar system. Few researches were interested in the integration energy and exergy analysis with PCMs at medium and high melting temperature. So, this paper becomes to study experimentally the energy/exergy analysis of a constructed thermal storage unit, and investigate how the temperature within PCMs and the exergy efficiency changes with time. The objective of this study is to analyze experimentally a TSU during phase change mode (latent energy mode) from an energy and exergy perspective. The effect of the operating parameters on the analysis will also be investigated.

\section{Energy and exergy analysis}

The analysis of energy for the current work is conducted using the concept thermodynamics first law. It provides stored and recovered energy through storage process. Cumulative input energy $\left(\mathbf{Q}_{\text {in }}\right)$ stored in the PCMs during charging periods for constant fluid mass flow rate $\left(\dot{\mathbf{m}}_{\mathbf{f}}\right)$ is listed (Dincer and Rosen, 2007; Hosseini and Bahrampoury, 2014):

$\mathrm{Q}_{\text {in }}=\dot{\mathrm{m}}_{\mathrm{f}} \mathrm{c}_{\mathrm{f}} \int_{0}^{\mathrm{t}}\left(\mathrm{T}_{\text {in }}-\mathrm{T}_{\text {out }}\right) \mathrm{dt}$

Where $\mathrm{T}_{\text {in }}$ and $\mathrm{T}_{\text {out }}$ are inlet and outlet fluid temperature of energy storage, $\mathrm{C}_{\mathrm{f}}$ is fluid specific heat. A fully insulated unit made the energy gained by fluid is completely stored in the PCMs. The energy delivered $\left(Q_{\text {out }}\right)$ from PCMs to fluid during discharging period for constant mass flow rate of fluid is written as follows (Dincer and Rosen, 2007; Hosseini and Bahrampoury, 2014):

$\mathrm{Q}_{\text {out }}=\dot{\mathrm{m}}_{\mathrm{f}} \mathrm{c}_{\mathrm{f}} \int_{0}^{\mathrm{t}}\left(\mathrm{T}_{\text {out }}-\mathrm{T}_{\mathrm{in}}\right) \mathrm{dt}$

Eq.3 is used to examine the behavior of the latent of TSU and to measure how much warmness or coldness is stored, overall energy efficiency for charging and discharging process, Eq. 3 is used

$\eta=\frac{Q_{\text {out }}}{Q_{\text {in }}}$

Exergy analyses enable us to find the maximum potential associated within the incoming thermal energy. Also stored and recovered energy quality is also provided by the analysis. The maximum potential of energy will retain and recover in case of a reversible way but the actual process is always irreversible therefore the exergy is not conserved as energy. The exergy analysis using the concept of second law is presented here in for charging and discharging process. The exergy input rate $\left(\mathrm{EX}_{\text {in }}\right)$ by fluid to $\mathrm{PCM}$ sor constant mass flow rate during charging periods at certain ambient temperature $\left(\mathrm{T}_{\mathrm{amb}}\right)$ is introduced by Eqs. (4), (5), and (6) correspondingly (Jegadheeswaran et al. 2010; Mahfuz et al. 2014)

$\mathrm{EX}_{\text {in }}=\dot{\mathrm{m}}_{\mathrm{f}} \mathrm{c}_{\mathrm{f}} \int_{0}^{\mathrm{t}}\left[\left(\mathrm{T}_{\text {in }}-\mathrm{T}_{\text {out }}\right)-\mathrm{T}_{\mathrm{amb}} \ln \left(\frac{\mathrm{T}_{\text {in }}}{\mathrm{T}_{\text {out }}}\right)\right] \mathrm{dt}$

The exergy stored $\left(\mathrm{EX}_{\mathrm{st}}\right)$ in the PCMSs is given by the following equation:

$\mathrm{EX}_{\mathrm{st}}=\dot{\mathrm{m}}_{\mathrm{f}} \mathrm{c}_{\mathrm{f}} \int_{0}^{\mathrm{t}}\left[\left(\mathrm{T}_{\mathrm{in}}-\mathrm{T}_{\text {out }}\right)\left(1-\frac{\mathrm{T}_{\mathrm{amb}}}{\mathrm{T}_{\mathrm{PCMs}}}\right)\right] \mathrm{dt}$ 
While the exergy recovered $\left(\mathrm{EX}_{\text {out }}\right)$ from the PCMS to fluid for constant mass flow rate during discharging periods is expressed as follows:

$\mathrm{EX}_{\text {out }}=\dot{\mathrm{m}}_{\mathrm{f}} \mathrm{c}_{\mathrm{f}} \int_{0}^{\mathrm{t}}\left[\left(\right.\right.$ out $\left.\left.-\mathrm{T}_{\text {in }}\right)-\mathrm{T}_{\mathrm{amb}} \ln \left(\frac{\mathrm{T}_{\text {out }}}{\mathrm{T}_{\mathrm{in}}}\right)\right] \mathrm{dt}$

Eqs. (7), (8), and (9) are used to calculate the exergy efficiency for a closed TSU during charging, discharging, and overall process ( Dincer and Rosen, 2010 )

$\Psi_{\text {charging }}=\frac{\mathrm{EX}_{\mathrm{st}}}{\mathrm{EX}_{\mathrm{in}}}$

The exergy efficiency for a closed TSU during discharging process is given by:

$\Psi_{\text {discharging }}=\frac{\mathrm{EX}_{\text {out }}}{\mathrm{EX}_{\mathrm{st}}}$

The overall exergy efficiency of PCMs storage can be found Eq. 9 as follows

$\Psi_{\text {overall }}=\Psi_{\text {charging }} \times \Psi_{\text {discharging }}$

\section{Experimental setup}

An experimental set-up of TSU was designed and constructed to investigate the efficiency and performance during charging and discharging modes. An experimental set-up was carried out by Olimat , (2016) is given in Fig. 1. Thermodynamic performance of TSU is sought to manipulate the effectiveness of the unit. The main component of cycle was the energy source whereas; cold storage container was the main element in discharging part. Heat exchanger with fins was used to motivate heat transfer between the PCMs and fluid. The vessel which contained PCMs was a rectangular box constructed from stainless steel having 73 Liters in volume with $4.0 \mathrm{~mm}$ thickness and it was placed horizontally. To enhance energy transfer, internal fins were placed vertically inside the container. Twenty six pieces of fins with $1.0 \mathrm{~mm}$ thickness and $1.0 \mathrm{~cm}$ spacing were used. To reduce the energy transfer to environment, the outer walls of the container were fully insulated using $5.0 \mathrm{~cm}$ thickness of ceramic fiber and gladded with $0.5 \mathrm{~mm}$ aluminum foil. To set the inlet temperatures at desired conditions and to control the flow rate volume; the source of energy was provided with a thermostat. Flow meter with an accuracy of $\pm 0.1 \%$ full-scale range was used to regulate the volume flow rate. Five K-type thermocouples are inserted in the container at different level to measure Transient temperature. To circulate oil, gear pump with motor capacity $2.0 \mathrm{hp}$ and $900 \mathrm{rpm}$ was used. Table. 1 introduced the used properties of the
Plus ICE H190 and XCEL THERM®600 (Radco Company, 2013; Phase Change Material Products Limited, 2013)

Table 1.

Thermo-physical properties of Plus ICE H190 and XCEL THERM®600

\begin{tabular}{lcc}
\hline Property & H190 & THERM ${ }^{\circledR 600}$ \\
\hline Phase change temp $\left({ }^{\circ} \mathrm{C}\right)$ & 191 & - \\
Density $\left(\mathrm{kg} / \mathrm{m}^{3}\right)$ & 2300 & 766.8 \\
Latent Energy $(\mathrm{kJ} / \mathrm{kg})$ & 170 & - \\
Vol. energy capacity $\left(\mathrm{MJ} / \mathrm{m}^{3}\right)$ & 1.51 & - \\
Heat Capacity $(\mathrm{J} / \mathrm{Kg} . \mathrm{K})$ & 1510 & 2470 \\
Thermal Conductivity $(\mathrm{W} / \mathrm{m} . \mathrm{K})$ & 0.512 & 0.1248 \\
Viscosity $($ Pa.s $) \times 10^{-4}$ & - & 9.45
\end{tabular}

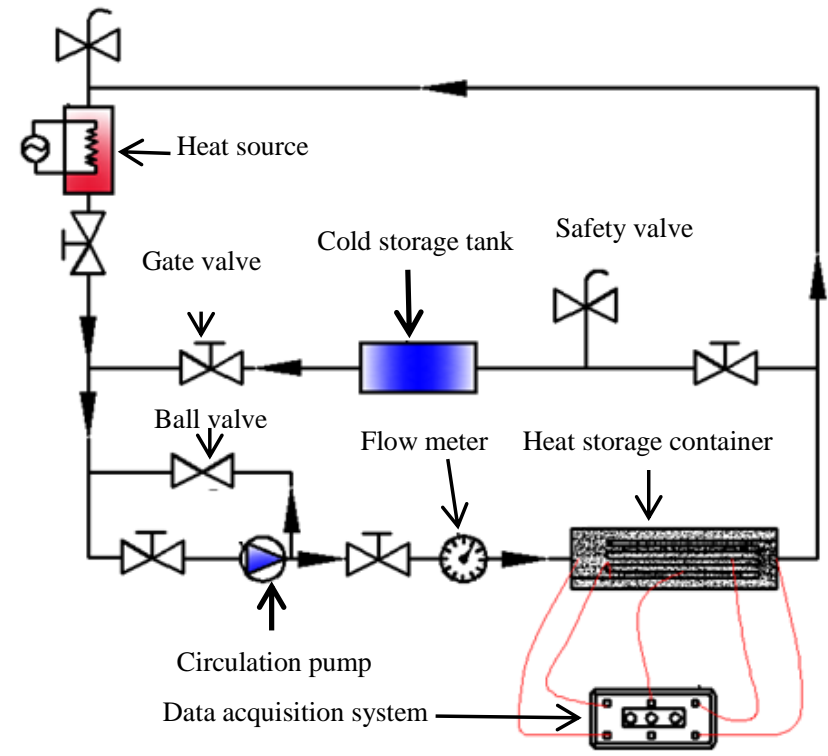

Figure 1. Schematic diagram of thermal storage unit.

\section{Results and discussion}

The analysis was performed to evaluate thermal efficiency and performance of a TSU. Experimental study and measurements were conducted to study the influence of fluid operating parameters on the TSU performance. This was carried out during charging and discharging processes using the curves of tested PCMs. The performance and energy transfer during phase change modes are functions of temperature, time, and thermal resistance.

The overall temporal variations for complete, charging and discharging, cycle of the PCMs temperature within the domain of TSU is shown in Fig. 2. PCMs temperature as shown in Fig. 2 is the average temperature of five thermocouple readings that inserted within the TSU at different locations. The 
Citation: Olimat, A.N., Awad, A.S., Al-Gathain, F.M., and Shaban, N.A.. (2017) Performance of Loaded Thermal Storage Unit With A Commercial Phase Change Materials Based on Energy and Exergy Analysis. Int. Journal of Renewable Energy Development, 6(3),283-290, doi.org/ijred.6.3.283-290

P a g e | 286

inlet temperature for fluid through charging process was $250^{\circ} \mathrm{C}$ and the ambient temperature was $10^{\circ} \mathrm{C}$. The fluid mass flow rates for charging and discharging processes were $2.5 \mathrm{~kg} / \mathrm{min}$ and $1.26 \mathrm{~kg} / \mathrm{min}$, respectively. The mass flow rate of charging process was higher than that of discharging process in order to get a quick melting of the PCMs and a reasonable longer solidification process. The longer time for solidification leads to increase the time of constant temperature during phase change process which implies to increase the achieved latent energy of solidification. The experimental results illustrate that the transition temperature of the PCMs is started to melt at $180^{\circ} \mathrm{C}$ and completed at $190^{\circ} \mathrm{C}$. The duration time required for the PCMs to complete melting process is approximately 20 minutes. Also, the time required for the PCMs to complete solidifying is approximately 30 minutes during solidification period. The solidification period of the PCMs is initiated at $180^{\circ} \mathrm{C}$ and completed at $170^{\circ} \mathrm{C}$. This reflects the influence of achieved latent energy during melting or solidification modes at approximately constant temperature. When the time for melting or solidification increased, the amount of achieved latent energy increased. As seen in Fig. 2, at the beginning of the charging period, the PCMs temperature increased by $200 \mathrm{C}$ through 20 minutes, this amount of energy is stored in the PCMs as a sensible energy. Also, the time needed to reduce the temperature by $20^{\circ} \mathrm{C}$ is 10 minutes at the beginning of the discharging period where energy is released as a sensible energy.

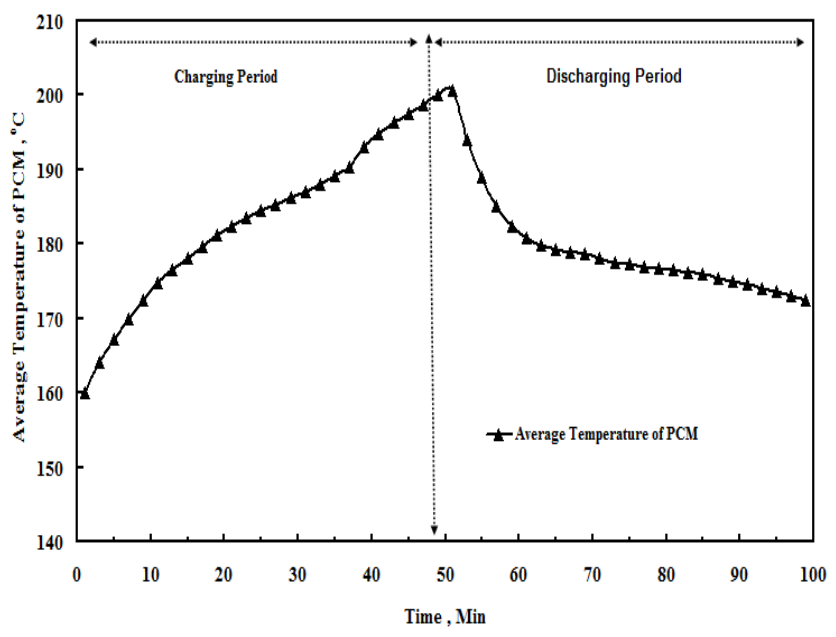

Figure 2. Historical average phase change material temperature through thermal storage unit at mass flow rate, $\dot{\mathrm{m}}_{\text {charging }}=$ $2.5 \mathrm{~kg} / \mathrm{min}, \dot{\mathrm{m}}_{\text {dischar }}=1.26 \mathrm{~kg} / \mathrm{min}$.

Figure 3 indicates Log Mean Temperature Difference (LMTD) variations of the PCMs inside the TSU during the charging process using the following equation (Dincer, M.A. Rosen , 2011)

$$
\Delta \mathrm{T}_{\mathrm{LMTD}}=\frac{\left(\mathrm{T}_{\text {in }}-\mathrm{T}_{\mathrm{PCMs}}\right)-\left(\mathrm{T}_{\text {out }}-\mathrm{T}_{\mathrm{PCMs}}\right)}{\ln \frac{\left(\mathrm{T}_{\text {in }}-\mathrm{T}_{\mathrm{PCMs}}\right)}{\left(\mathrm{T}_{\text {out }}-\mathrm{T}_{\mathrm{PCMs}}\right)}}
$$

Where Tin and Tout are inlet and outlet fluid temperatures, respectively; TPCMs is average phase change material temperature. From the results, the instant LMTD at the beginning is comparatively large compared with that at the final stage. By the time, the LMTD decreases due to the smaller values of enthalpies. It is decreased as the portion of the PCMSs melted or solidified is increased. The LMTD during melting periods is ranged between $25-30^{\circ} \mathrm{C}$. While the overall temporal variations for charging and discharging give a good indication for the system efficiency and performance, the LMTD enables us to predict the instantaneous thermal resistance during charging and discharging periods.

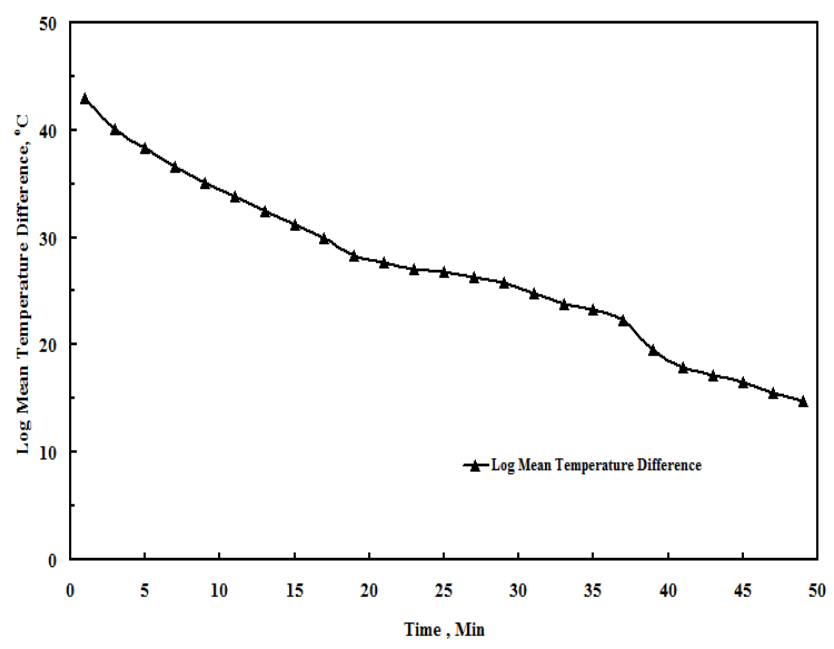

Figure 3. Variation of $\log$ mean temperature difference during charging process at fluid mass flow rate $2.5 \mathrm{~kg} / \mathrm{min}$

Dependence on liquid fraction of PCMs, $\varepsilon$, due to phase change and latent energy of the PCMs, H, the latent energy of enthalpy, $\mathrm{H}$ enthalpy, can be expressed as follows

$\mathrm{H}_{\text {enthalpy }}=\varepsilon \times \mathrm{H}$
$\varepsilon=\frac{\mathrm{T}-\mathrm{T}_{\text {solid }}}{\mathrm{T}_{\text {melt }}-\mathrm{T}_{\text {solid }}}$

Where, $\mathrm{T}_{\text {solid }}$ and $\mathrm{T}_{\text {melt }}$ denote the solidification and melting temperature, respectively. The variation of latent energy enthalpy with time during phase change is shown in Fig.4. The lower zone of the figure indicates that the enthalpy increases much faster with ascending enthalpy profile in the early stages. This rise is due to the liquid fraction which grows more rapidly at the beginning of the PCMs melted. 


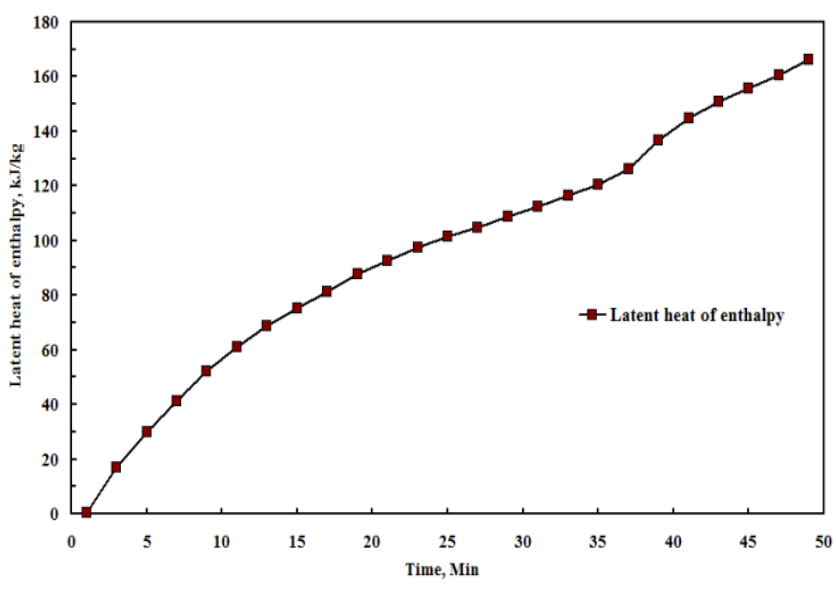

Figure 4. Temporal variation of latent energy of enthalpy of PCMSs at mass flow rate $2.5 \mathrm{~kg} / \mathrm{min}$

Using LMTD of PCMs with the energy rate input from fluid to the PCMs, The instant thermal resistance between fluid and PCMs is calculated according to the following relation:

$$
\mathrm{R}_{\text {thermal }}=\frac{\Delta \mathrm{T}_{\mathrm{LMTD}}}{\dot{\mathrm{m}}_{\mathrm{f}} \mathrm{c}_{\mathrm{f}} \Delta \mathrm{T}}
$$

Fig. 5 and Fig. 6 illustrate the instantaneous thermal resistance for charging and discharging modes. Convection energy transfer and the conduction thermal resistance are governed factors which influence melting rate. The results reveal that conduction thermal resistance of the thermal storage system varied linearly with time. Figure 5 shows that as the instantaneous thermal resistance is decreased, the performance of the system is increased due to the increase in energy transfer rate from fluid to the PCMs during charging process and vice versa occurs during discharging process as shown in Fig. 6. The conduction thermal resistance is dominant at the beginning of process because of its high value so the energy transfer is relatively high. The energy transfer in the unit is function of the thermal resistance between fluid and PCMs proportion which has already changed in phase. Thus the output of energy transfer is determined by the thermal resistance value in the unit and is limited by the phase change transition temperature. When the outlet temperature is equal to the phase change transition temperature, the transferred energy is maximum.

Fig. 5 and Fig. 6 present a mathematical correlation between thermal resistance and time. Linear regression of the plotted points is used to find intercept and slope relationship. The thermal resistance (K.s/J) as function of time (min) during charging and discharging respectively is:

$$
\begin{array}{ll}
\mathrm{R}_{\text {thermal }}=0.0269-0.0003 \mathrm{t} & \mathrm{R}^{2}=0.96 \\
\mathrm{R}_{\text {thermal }}=0.0360-0.0007 \mathrm{t} & \mathrm{R}^{2}=0.94
\end{array}
$$

Linear regression coefficient $\left(\mathrm{R}^{2}\right)$ for thermal resistance was $96 \%$ and $94 \%$, respectively. The high value of $\mathrm{R}$ squared indicates that there is goodness of fit for measured data.

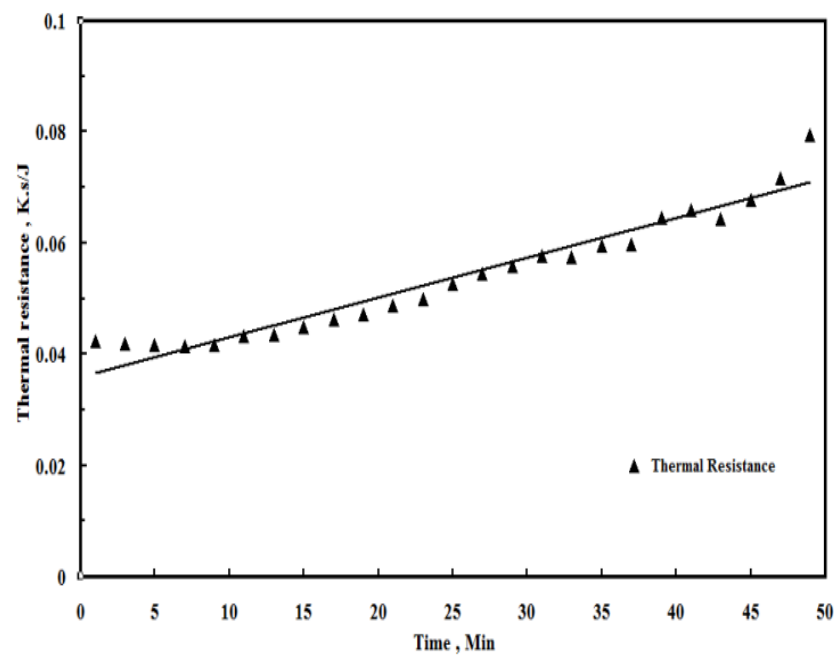

Figure 5. Instant thermal resistance during charging process at mass flow rate $2.5 \mathrm{~kg} / \mathrm{s}$

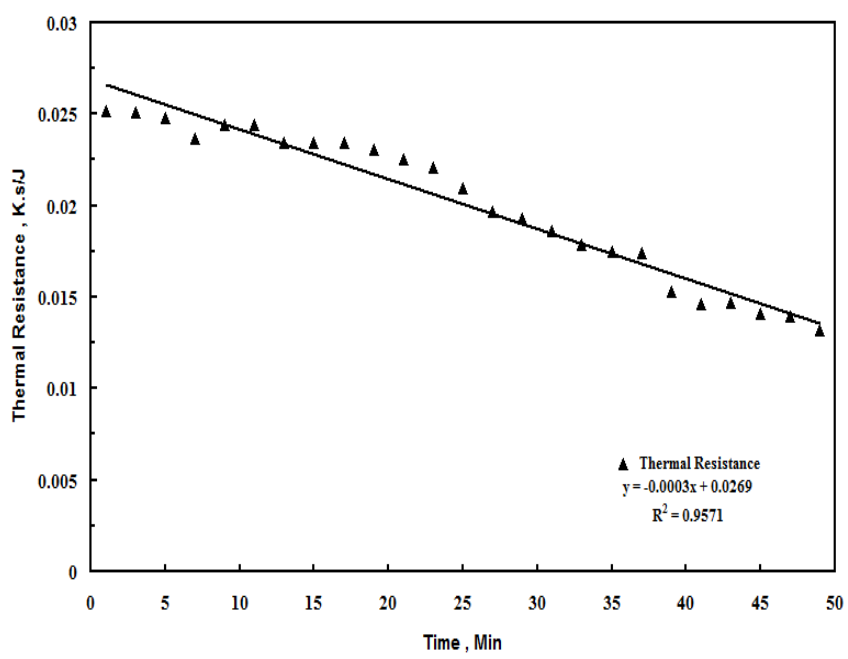

Figure 6. Instant thermal resistance during discharging process for mass flow rate $=1.26 \mathrm{~kg} / \mathrm{s}$

Variations of instantaneous temperature difference during charging process at fluid mass flow rate 2.5 $\mathrm{kg} / \mathrm{min}$ is presented in Fig. 7 based on the experimentally achieved results. It illustrates the difference between the fluid temperature and PCMs temperature and the difference between fluid inlet and outlet temperature with time. As the difference between the two curves is reduced, better effectiveness of the system is obtained (as shown in Fig. 8) especially in the latent energy zone (isothermal behavior) or phase change zone. The driving force for the energy transfer is the difference between the fluid temperature and PCMs temperature. As the difference 
Citation: Olimat, A.N., Awad, A.S., Al-Gathain, F.M., and Shaban, N.A.. (2017) Performance of Loaded Thermal Storage Unit With A Commercial Phase Change Materials Based on Energy and Exergy Analysis. Int. Journal of Renewable Energy Development, 6(3),283-290, doi.org/ijred.6.3.283-290

P a g e | 288

between fluid inlet temperature and PCMs temperature increased, the energy transfer achieved and the total stored energy are increased. The resulted energy and exergy rate and the time of melting or solidification are influenced with this difference. When the two curves became close to each other, the process reached the steady state conditions and the charging process is finished. Therefore, the accumulated rate of energy approaches its maximum, thus energy transfer will decreases, which means the influence of sensible energy in comparison with latent energy, is very small.

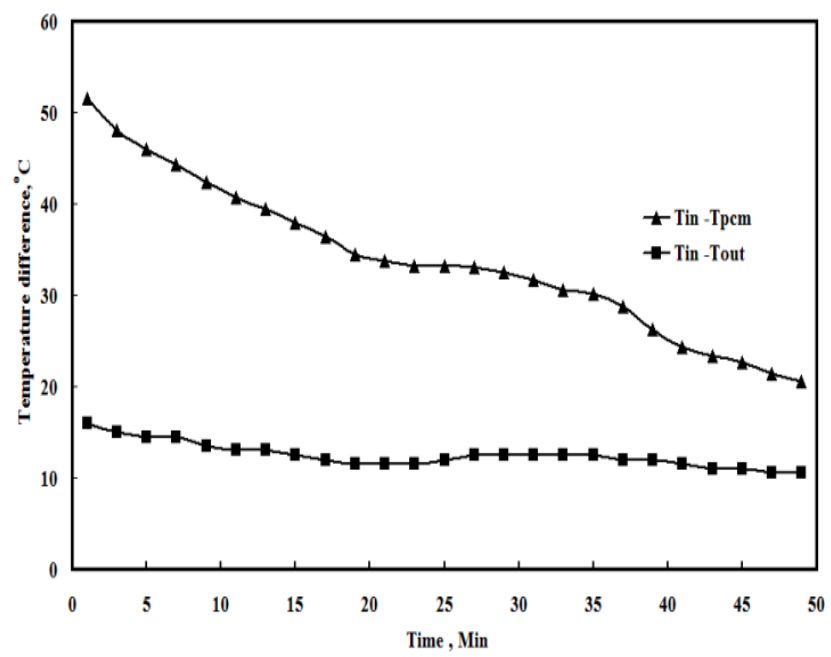

Figure 7. Instantaneous temperature difference during charging process at fluid mass flow rate $2.5 \mathrm{~kg} / \mathrm{min}$

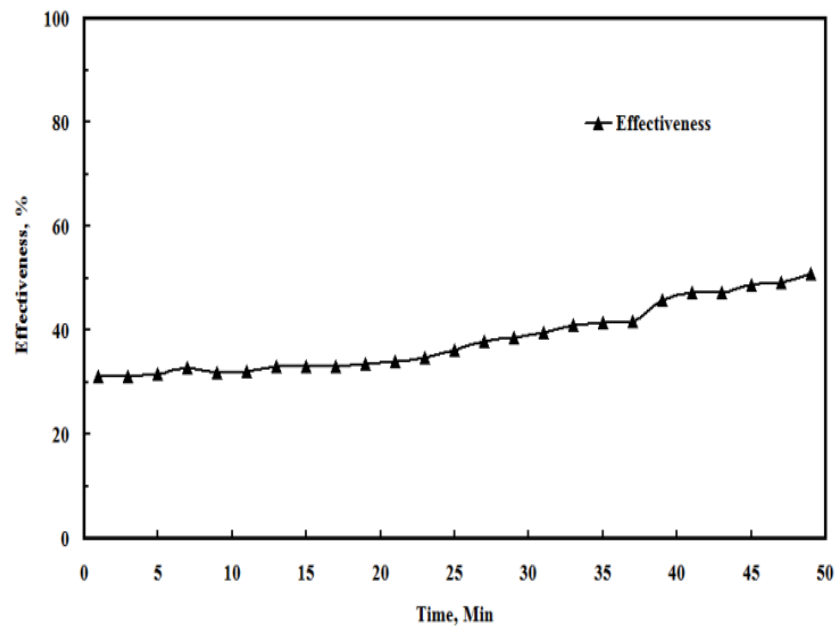

Figure 8. Instantaneous effectiveness during charging process at fluid mass flow rate $2.5 \mathrm{~kg} / \mathrm{min}$

Energy rate and exergy rate in TSU during charging and discharging time were calculated using Equations 1 to 2 respectively. A comparison of the exergy and energy analyses is presented in Figs. 9, 10 and 11 . The change of rates of energy and exergy in the TSU during the time are illustrated in Fig. 9 and Fig. 10. As shown in the figures at the beginning, the higher difference between fluid and PCMs temperature leads to higher instant of energy transfer. Moreover, the instantaneous rate of rate of energy tends to reduce with time because the effect of difference in temperature is relatively reduced. Rate in TSU ranged from 1.1 to $1.7 \mathrm{~kW}$, while the exergy rate ranged from 0.5 to $0.7 \mathrm{~kW}$. The behavior of the rate of exergy shown in the figure indicates that there is destruction in the rate of exergy after the melting or solidification modes. The destruction of exergy is due to irreversibility factors which is associated with viscous dissipation and with energy transfer. The rate of energy transfer in TSU during discharging periods ranges between 0.55 and $1.56 \mathrm{~kW}$, while exergy rate is ranging from 0.16 to $0.44 \mathrm{~kW}$. On the charging periods, the average energy rate and exergy rate were $1.30 \mathrm{~kW}$ and $0.54 \mathrm{~kW}$, respectively whereas the energy rate and exergy rate were $1.10 \mathrm{~kW}$ and $0.31 \mathrm{~kW}$, respectively during discharging periods. Difference between energy and exergy rate in TSU could be explained as following: during the experimental stages, the average energy rate of energy was higher than rate exergy during charging periods. As the rate of exergy depends directly on the fluid temperature and its ambient temperature, the energy rate increased due to the inlet and outlet temperatures difference. The results showed that the global energy and exergy efficiency were $84 \%$ and 54 $\%$, respectively. Comparing the global energy efficiency with the overall exergy efficiency, the following results can be concluded:

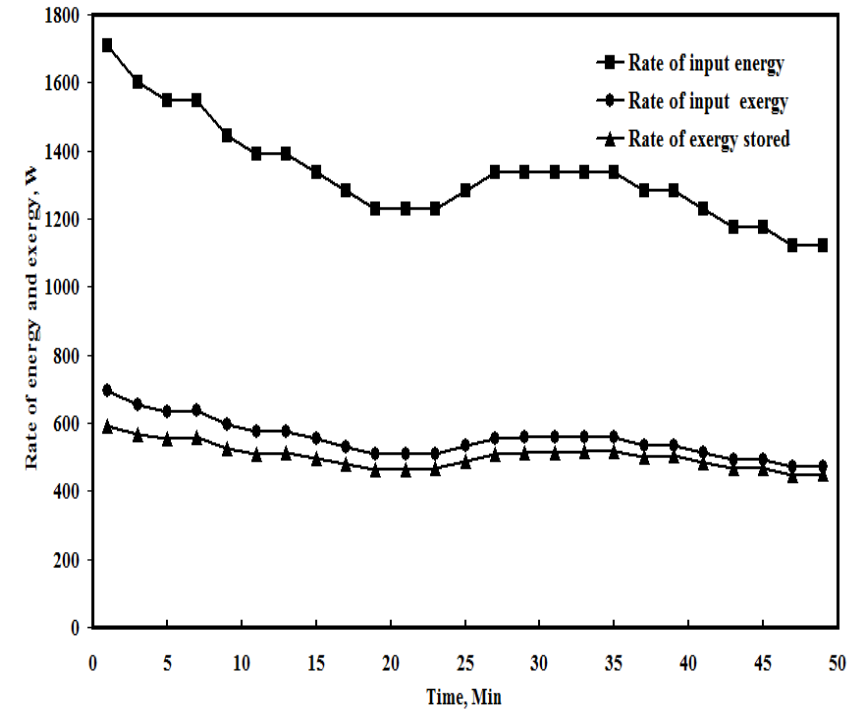

Figure 9. Rate of thermal energy and thermal exergy variation at fluid mass flow rate $2.5 \mathrm{~kg} / \mathrm{min}$

Firstly, the hot fluid energy content, which is used in calculating energy efficiency leads to make the global energy efficiency, is higher than exergy efficiency. Secondly, degradation of temperature through transferring or storing energy make also the exergy efficiency is less than the energy efficiency. Temperature degradation is reflected on the exergy efficiency and but the energy efficiency, thus the exergy efficiency is more meaningful. Thirdly, exergy analysis 
considers the irreversibility factors during storage operations, and hence it is more correctly reflects the thermodynamic value. In addition, exergy efficiency is a measure of the quality of energy, so it is more significant than energy efficiency, thus it is more useful tool to compare between thermal energy systems.

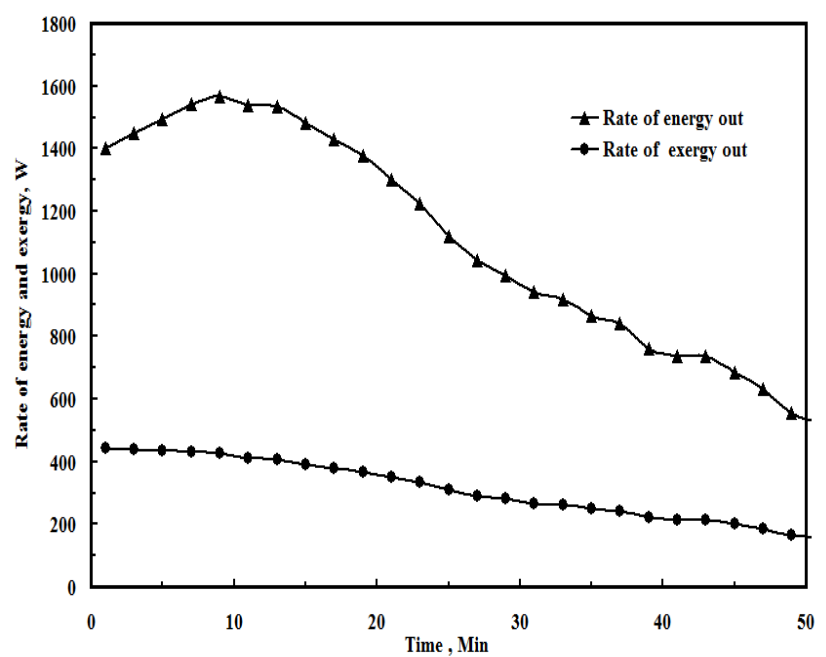

Figure 10. Rate of thermal energy and thermal exergy variation at fluid mass flow rate $1.26 \mathrm{~kg} / \mathrm{min}$

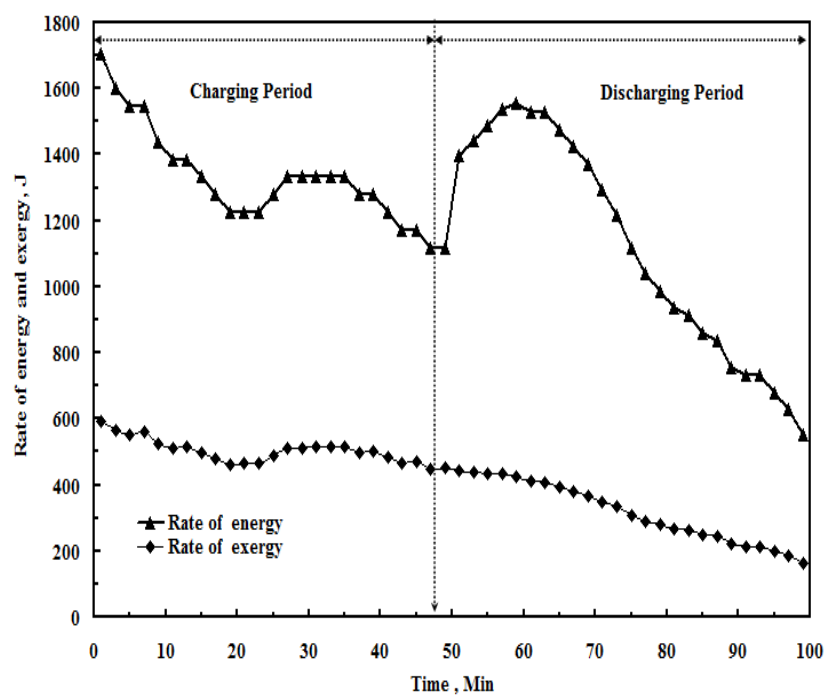

Figure11. Rate of thermal energy and exergy overall variations for fluid mass flow rate $2.5 \mathrm{~kg} / \mathrm{min}$ and $1.26 \mathrm{~kg} / \mathrm{min}$, respectively.

\section{Conclusion}

In the current study, energy and exergy analysis of TSU integrated with commercial PCMs, PlusICE H190, at medium melting temperature are sought. Melting and solidification of the selected PCMSs are experimentally investigated in this study by using the average value of five temperature readings inserted at different heights within the domain of storage unit. The exergy analysis of PCMSs is considered as one of the powerful methods to measure usefulness of the PCMSs. The effectiveness of thermal storage unit on the basis of the principle of energy and exergy efficiencies has been determined at a certain conditions during the transition temperature of the phase change material. The inlet temperature for fluid thorough charging process is $250^{\circ} \mathrm{C}$ at the ambient temperature $10 \mathrm{oC}$. Fluid mass flow rate for charging and discharging processes are $2.5 \mathrm{~kg} / \mathrm{min}$ and $1.26 \mathrm{~kg} / \mathrm{min}$, respectively. The following results are obtained:

- Phase change materials at the transition temperature give higher values of exergetic efficiency.

- Phase change materials can be used to store thermal energy at the transition temperature of the PCMs to improve the overall performance.

- The energy and exergy rate and the time of melting or solidification are influenced with temperature difference between fluid inlet and PCMs temperatures.

- The difference between the energy and exergy rate analysis is remarkable.

- Thermal resistance is dominant such that as thermal resistance is decreased with time, the performance of the system increased due to increase energy transfer rate between fluid and PCMs.

- The selected commercial PCMs (PlusICE H190), is suitable to store energy at intermediate temperature $\left(160-200^{\circ} \mathrm{C}\right)$ applications.

- The thermal energy efficiency of storage units is around $84 \%$ while the exergy efficiency of the unit is about $54 \%$.

- The thermal energy and exergy average rates are $1.3 \mathrm{~kW}$ and $0.54 \mathrm{~kW}$, respectively. Also the average thermal energy and exergy are $1.1 \mathrm{~kW}$ and 0.31 $\mathrm{kW}$.

\section{Nomenclature}

$Q_{\text {in }} \quad$ : Input heat, $\mathrm{J}$

$\dot{\mathrm{m}}_{\mathrm{f}} \quad$ : Mass flow rate, $\mathrm{kg} / \mathrm{min}$

$\dot{\mathrm{m}}_{\mathrm{f}} \quad$ : Mass flow rate, $\mathrm{kg} / \mathrm{min}$

PCMs : Phase change materials

$\mathrm{C}_{\mathrm{f}} \quad$ : Heat capacity of PCMs, J/kg.K

$\mathrm{T}_{\text {in }} \quad$ : Inlet fluid temperature, ${ }^{\circ} \mathrm{C}$

$\mathrm{T}_{\text {out }} \quad$ : Outlet fluid temperature, ${ }^{\circ} \mathrm{C}$

$\mathrm{T}_{\mathrm{pcm}} \quad$ : Phase change materials temperature, ${ }^{\circ} \mathrm{C}$

$\mathrm{T}_{\text {melt }} \quad$ : Melting temperature of the PCMSs, ${ }^{\circ} \mathrm{C}$

$\mathrm{T}_{\text {solid }} \quad$ : Solidification temperature of the $\mathrm{PCMSs}^{\circ} \mathrm{C}$

$\mathrm{Q}_{\text {out }} \quad$ : Output heat, J

$\mathrm{EX}_{\text {in }} \quad$ : Input exergy, $\mathrm{J}$

EX $_{\text {out }}$ : Output exergy, J

$\mathrm{EX}_{\text {st }} \quad$ : Stored exergy, $\mathrm{J}$

$\mathrm{T}_{\mathrm{amb}} \quad$ : Ambient temperature, ${ }^{\circ} \mathrm{C}$

$\Delta \mathrm{T}_{\mathrm{LMTD}}:$ Log mean temperature difference, ${ }^{\circ} \mathrm{C}$

$\Delta \mathrm{T} \quad$ : Temperature difference, ${ }^{\circ} \mathrm{C}$

$\mathrm{R}_{\text {thermal }}:$ Thermal resistance, K.s/J

$\mathrm{H}$ : Latent heat of the material, $\mathrm{kJ} / \mathrm{kg}$

ESS : Energy storage system

$\mathrm{H}_{\text {enthalpy }}$ : Latent heat of enthalpy, kJ/kg 
Citation: Olimat, A.N., Awad, A.S., Al-Gathain, F.M., and Shaban, N.A.. (2017) Performance of Loaded Thermal Storage Unit With A Commercial Phase Change Materials Based on Energy and Exergy Analysis. Int. Journal of Renewable Energy Development, 6(3),283-290, doi.org/ijred.6.3.283-290

P a g e | 290

$\varepsilon \quad$ : Liquid fraction of phase change materials

$\eta \quad:$ Overall efficiency, $\%$

$\boldsymbol{\Psi} \quad$ : Exergy efficiency, \%

\section{References}

Aghbalou, F. and Badia F. (2006) Exergetic optimization of solar collector and thermal storage unit. Int. J. Energy Mass Trans, 49, 1255-1263.

Asbik, M, Ansari, O., Bah, A., Zari, N., Mimet, A. and El-Ghetany, H. (2016). Exergy analysis of solar desalination still combined with energy storage system using phase change material (PCMS). Desalination, 381, 26-37.

Bouadila,S. Lazaar,M. Skouri, S., Kooli, S., and Farhat. A. (2014) Energy and exergy analysis of a new solar energy with latent storage energy. Hydrogen energy, 39, 15266-15274.

Dincer, I., and M. A. Rosen. (2010) Energy and exergy analyses of thermal storage units, Thermal Energy Storage. John Wiley \& Sons, Ltd., UK, 233-334.

Dincer, I., and M. A. Rosen. (2011) Thermal storage units and applications, 2nd Ed., John Wiley \& Sons, Ltd., UK, 274275 .

Dincer, I., and Rosen.M.A. (2007) Exergy: energy, environment, and sustainable development, Elsevier Science, UK.

Erek A., and Dincer I. (2009) A new approach to energy and exergy analysis of latent energy storage unit. Energy Trans. ENG, 49, 506-525.

Farid, M. M. Khudhair, A. M, Razack, S. A. K., and Al-Hallj, S. (2004) A review on phase change energy storage materials and applications. Energy convers manage, 45, 1597-1615.

Gang, L. (2015). Energy and exergy performance assessment for latent energy thermal storage units", Renewable and sustainable energy reviews. 51, 926-954.

Gang, L, Yunho, H. and Reinhard, R. (2014) Experimental investigation on energy and exergy performance of adsorption cold storage for space cooling applications. Refrigeration, 44, 23-35.

Hosseini, M. J., Rahimi, M. and Bahrampoury, R. (2014) Experimental and computational evaluation of a shell and tube energy exchanger as a PCMS thermal storage system. Int. Commun. Energy Mass Transfer, 50, 128-136.

Jegadheeswaran, S, S. D. Pohekar, and T. Kousksou. (2010) Exergy based performance evaluation of latent energy thermal storage system: a review. Renew. Sust. Energy Rev, 14 (9) , 2580-2595.

Jegadheeswarm, S., and Pohekar, S. D. (2010) Energy and energy analysis of particle dispersed latent energy storage system. International journal of energy and environment, 445-458.

Kaushik, S. C., Reddy, V. S., and Tyagi S. K., (2011) Energy and exergy analysis of thermal power plant: a review, Renew Sust. Energy Rev, 15, 857-1872.

Mahfuz, M. H., A. Kamyar, O. Afshar, M. Sarraf, M. R. Anisur, M. A. kibria, R. Saidur, and I.H. S. C. Metselaar. (2014) Exergetic analysis of a solar thermal power system with PCMS storage. Energy conversion and management. 78, 486-492.

Mahfuz, M. H., Anisur, M. R. Kibria, M. A. Saidur, R.and Metselaar, I. H. S. C. (2014) Performance investigation of thermal storage unit with phase change material (PCMS) for solar water energy application. International Communications in Energy and Mass Transfer, 57, 132-139.

Olimat, A. N., Al-Ghathian, F.M and Awad.A.S. (2016) Experimental study of thermal storage unit using fin tube energy exchanger and commercial phase change material. Research of Journal of Applied Sciences, Engineering and Technology, 13 (5), 394-402.

Phase Change Material Products Limited, PlusICE® phase change materials catalogue data, 2013.
Radco Company, Industrial energy fluid, XCEL THERM $₫ 600$, engineering fluid properties catalogue data, 2013

Sari, A., and Kaygusuz. K. (2004). First and second laws analysis of a closed latent energy thermal storage units. Chinese J. Chem. Eng. 12(2), 290-293.

Verma, P., Varun, and Singal, S.K. (2008). Review of mathematical modeling on latent energy thermal storage units using phase change material. Renew Sust. Energy Rev, $12,999-1031$ 